\title{
MICROPHOTOMETRIC METHOD FOR MEASURING THE OXYGENATION AND DEOXYGENATION RATE IN A SINGLE RED BLOOD CELL
}

\author{
Tsukasa $\mathrm{ONO}^{1}$ and Hiroshi TAZAWA* \\ Research Institute of Applied Electricity, Hokkaido University, Sapporo 060 \\ *Department of Physiology, Yamagata University School of Medicine, \\ Yamagata 990-23, Japan
}

\begin{abstract}
A new reaction apparatus combining a microscope and a photometric device was developed for kinetic studies of a single red cell. A monolayer of red cells was placed in a closed reaction cuvette set on a microscope stage, a light beam of 5 to $10 \mu \mathrm{m}$ in diameter was directed into one of the red cells, and the light transmission change in the cell was analyzed. The light beam with a wavelength range shorter than $460 \mathrm{~nm}$ was made by placing a narrow iris diaphragm in the light path. The space in the cuvette prevented the red cells from drying thereby providing favorable physiological conditions during measurements. The cuvette was filled with reagent gas mixtures of $\mathrm{O}_{2}, \mathrm{CO}_{2}$, and $\mathrm{N}_{2}$ which came in contact with the red cells. Transmission change due to the reaction was detected separately at two wavelengths of 418 and $402 \mathrm{~nm}$ by means of two photomultipliers mounted on the microscope. The linearity was tested by comparison between $S_{\mathrm{O}_{2}}$ measured with a Van-Slyke apparatus and the microphotometer. Both $S_{\mathrm{O}_{2}}$ measurements agreed well with each other, but the latter was about $3 \%$ greater than the former at around $50 \% \mathrm{~S}_{\mathrm{O}_{2}}$. Using this apparatus the oxygenation and deoxygenation velocities were measured over an entire $\mathrm{O}_{2}$-saturation range. The velocity factors showed good agreement with those obtained by using conventional flow methods.
\end{abstract}

The reaction rate of a red cell with $\mathrm{O}_{2}$ has been measured so far by using the rapid or stopped flow methods (HARTRIDGE and ROUGHTON, 1923; ForSTER et al., 1957; StAub et al., 1961; MochizUKI, 1966a). In these methods the following technical problems have been pointed out. Oxygen tension in the reacting solution changes during the reaction process, therefore, the deoxygenation velocity, for instance, cannot be measured over an entire range of $\mathrm{O}_{2}$-saturation by mixing the

Received for publication July 15, 1974

1 Present address: Department of Physiology, Yamagata University School of Medicine, Yamagata 990-23, Japan.

小野 束, 田沢 皓 
oxygenated red cell suspension with an $\mathrm{O}_{2}$-free solution (MocHIzUKI, 1966b). In addition, in the rapid flow method the oxygenation velocity of the red cell receives considerable influence from the flow rate of the suspension through the observation tube (Koyama and Mochizuki, 1969). In order to improve the above technical and physiological problems, the present authors have developed a microphotometer.

One of the most significant features in this microphotometer is its capability to measure the transmission change in the light beam passing through the single red cell directly contact with reagent gases. This technique has various advantages; 1) $\mathrm{PO}_{2}$ can be kept constant through the reaction, 2) the deoxygenation velocity can be measured by using $\mathrm{N}_{2}$ gas instead of dithionite $\left(\mathrm{Na}_{2} \mathrm{~S}_{2} \mathrm{O}_{4}\right)$ solution (LAWSON et al., 1965), 3) only a small amount of blood sample is needed, 4) the reaction rate of red blood cells in the capillaries can be measured (MochIZUKI et al., 1973; TAZAWA et al., 1974). One shortcoming of the microphotometric method is that a red cell exposed to gas easily dries up during the course of measurement. However, this has been overcome by covering the red cells with a thin transparent silicone membrane.

In this report the microphotometric method for measurement of reaction rate will be described based on the data obtained with the apparatus which we recently developed.

\section{METHODS}

1) The structure of the microphotometric reaction apparatus. The basic principle of the microphotometer is to detect the transmission change of a light beam, 5 to $10 \mu$ in diameter, which penetrates through a single red cell surrounded by a reagent gas. It is composed mainly of a reaction cuvette, a light source and a photometric system which are all attached to the microscope. The setup is schematically illustrated in Fig. 1.

A 300-watt tungsten lamp was used as the light source. Its intensity was adjusted by varying the output voltage of a stabilized DC source to match a favorable sensitivity of the photomultipliers. The light from the lamp was first converged by lenses 1 after passing through a heat filter. To exclude undesirable heat effects, incident light with a wavelength range longer than $460 \mathrm{~nm}$ was removed by use of a dichroic mirror. Since the light beam converged by lenses 1 was still so wide that the whole field of the microscope vision was illuminated, it was further narrowed by using an iris diaphragm and lenses 2 so as to illuminate only one red cell. The dimension of the spot was adjustable to the same size as diameter of the red cell. The light beam passing through red cell was divided into two parts by a half mirror and the transmission change caused by the reaction was differentially detected with two sets of interference filters and photomultipliers. The transmitting wavelengths of the filters, chosen to produce a maximum change in transmission by referring to the data on the spectrograms of hemoglobin 


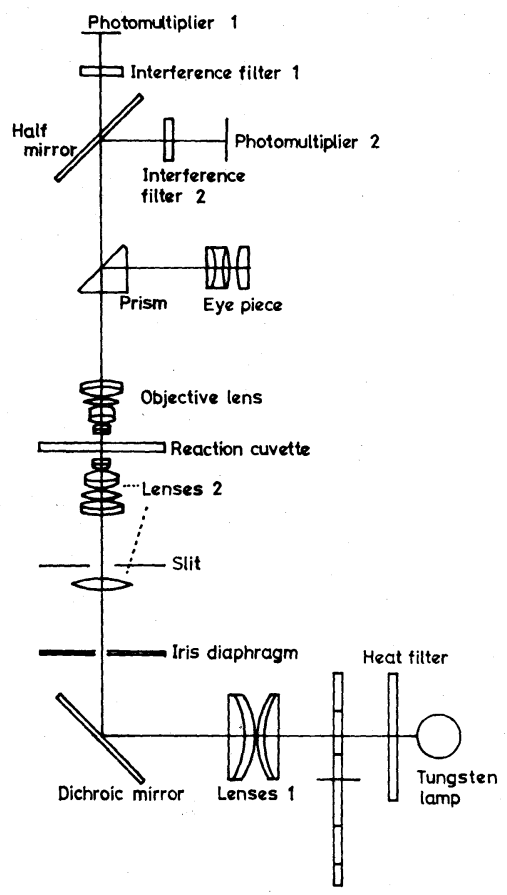

Fig. 1. Schema of the microphotometric reaction apparatus.

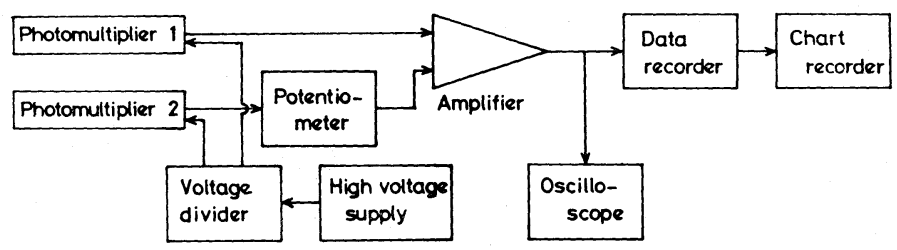

Fig. 2. Block diagram of the analyzing system.

solutions (FUKUI and MochizUKi, 1972), were 418 and $402 \mathrm{~nm}$. The two head-on window-type photomultipliers (Toshiba, 7696) are sensitive to wavelengths ranging from 300 to $650 \mathrm{~nm}$. The photomultipliers were set in an independent housing together with the interference filter to shield them from line frequency and external light. Figure 2 is a block diagram of the analysing system.

Because the photomultipliers show different sensitivities at the respective wavelengths of the interference filters, the voltage supplied to them (John Fluke, Model 412B) was adjusted by means of a voltage divider prior to the measurement to establish balance between their output currents. After the red cells were put in the reaction cuvette, the output signals were balanced to provide a maximum dynamic range of amplification by using a potentiometer connected to photo- 
multiplier 2 paired with the $418 \mathrm{~nm}$ interference filter. In the actual measurement of reaction the output signal was first stored in a data recorder and then reproduced on a chart recorder after experiments.

2) Reaction cuvette and other associated devices. The reaction cuvette must be thin enough to fit the narrow space between both the condenser lenses 2 and the objective lens. In addition, it should be air-tight and solid enough to bear the stress during exchange of the cell sample and flushing of the reagent gases. The distance between the lenses was about $1.9 \mathrm{~mm}$ at a magnification $400 \times$. Therefore, when the glass slide of about $1 \mathrm{~mm}$ thickness was used for the base plate of the cuvette for mechanical strength, the reaction space between the cover $(0.17 \mathrm{~mm})$

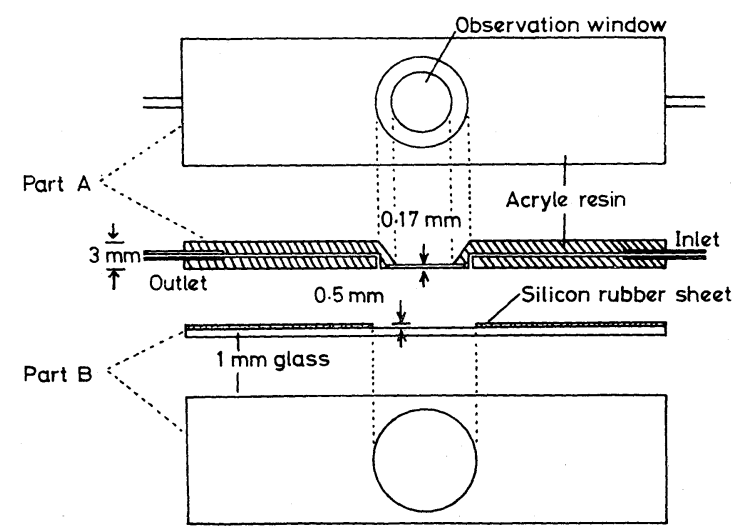

Fig. 3. Schema of the reaction cuvette.

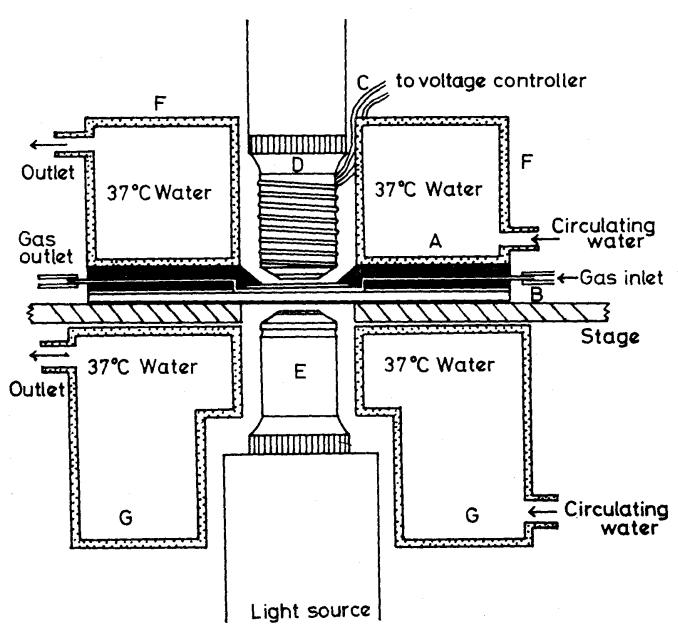

Fig. 4. Illustration of the reaction cuvette on the microscope stage together with the thermo-regulating baths. 
and glass slide became less than about $0.7 \mathrm{~mm}$. Thus, for convenience in exchanging the preparation sample, the reaction cuvette was constructed by joining together an upper part (A) and a lower part (B) as shown in Fig. 3. The cover glass of part $A$ was attached to a $3 \mathrm{~mm}$ acryle plate with the window in the center. The reagent gas was flushed through a $1 \mathrm{~mm}$ inner diameter channel drilled through the acryle plate as shown in the figure. On the glass slide of part B a silicone rubber sheet of $0.5 \mathrm{~mm}$ in thickness was attached to form the reaction space when both the parts were joined together. Thus, the reaction space had a dimension of $0.5 \mathrm{~mm}$ in height, $10 \mathrm{~mm}$ in diameter and about $0.04 \mathrm{ml}$ in volume, and had inlet and outlet connection tubings for the reagent gas. Figure 4 shows the reaction cuvette on the microscope stage together with thermo-regulating baths. Because measurement must be carried out at physiological temperature, the baths were kept at $37^{\circ} \mathrm{C}$ by circulating warm water. A heating wire wound around a cylinder of the objective lens was also used to maintain constant temperature. The temperature inside the cuvette was monitored with a pin head type thermister before each experiment.

After the red cells in the cuvette were brought into focus and a single red cell was illuminated, the reagent gas mixtures were introduced into the reaction space at a rate of 2 to $5 \mathrm{ml} / \mathrm{sec}$ using a $5 \mathrm{ml}$ glass syringe or a gas supplier. Syringes were installed with a three-way-stopcock and the gas was forced into the cuvette by means of a plunger. A gas supplier, with six 1-1-volume bottles was used mainly when oxygenation reaction was measured. The $\mathrm{O}_{2}$ gas mixtures of various concentrations in the bottles were released into the cuvette by pouring warm water into the bottles. Six sequential oxygenation steps were observed in the same red cell by using this supplier.

3) Effect of non-uniformity in thickness of the red cell upon the calibration curve of $\mathrm{O}_{2}$-saturation. The red cell has a biconcave shape when placed on a plate, that is, its thickness is not uniform; this gives rise to an error in $\mathrm{O}_{2}$-saturation. Thus, we attempted first to evaluate theoretically the extent of the error by using Lambert-Beer's equation.

In a hemoglobin solution the relation between intensities of incident and transmitted light obeys Lambert-Beer's law in the following manner:

$$
I=I o \cdot e^{-\varepsilon_{\lambda} \cdot c \cdot d}=I o\left[1-\varepsilon_{\lambda} \cdot c \cdot d+\left(\varepsilon_{\lambda} \cdot c \cdot d\right)^{2} / 2 !-\cdots\right],
$$

where $\varepsilon_{\lambda}$ is the extinction coefficient at wavelength $\lambda, c$ is the hemoglobin concentration and $d$ is the thickness of the solution layer. The above equation is thought to be applicable also to the analysis of the transmitted light through the red cell if the light beam is small enough to illuminate only a small section within the cell. However, in the present apparatus, as the beam illuminates the entire area of single red cell, a certain modification is necessarily required for Eq. (1) because of the non-uniform thickness of the cell. If the single red cell is divided into small sections, the total light intensity passing through all the sections is con- 
sidered to be an algebraic sum of the individual light intensities passing through each section. Hence, Eq. (1) may be rewritten as follows:

$$
I=I o\left[1-\varepsilon_{\lambda} \cdot c \cdot \bar{d}+\left(\varepsilon_{\lambda} \cdot c\right)^{2} \bar{d}^{2} / 2 !-\cdots\right]
$$

where

$$
\bar{d}=(1 / n) \sum_{1}^{n} d_{i}, \quad \tilde{d}^{2}=(1 / n) \sum_{1}^{n} d_{i}^{2} .
$$

When the $\mathrm{O}_{2}$-saturation, $S_{\mathrm{O}_{2}}$, is measured photometrically at two wavelength, one of which is chosen to be an isobestic wavelength, the $S_{\mathrm{O}_{2}}$ is determined from the following equation (ForsTER et al., 1957):

$$
S_{\mathrm{O}_{2}} \text { (meas.) }=\left(I_{\lambda t}-I_{\lambda 0}\right) /\left(I_{\lambda 1}-I_{\lambda 0}\right)=I_{t} / I_{1},
$$

where $I_{\lambda, 1}, I_{\lambda 0}$ and $I_{\lambda t}$ are the light intensities transmitted through the red cell with 100 and $0 \% S_{\mathrm{O}_{2}}$ saturation and at any level of $S_{\mathrm{O}_{2}}\left(S_{t}\right)$ observed during the oxygenation process. $I_{t}$ and $I_{1}$ in Eq. (4) are the amplitudes in a signal pattern as shown in Fig. 6. Using Eq. (4), we can calculate any $S_{\mathrm{O}_{2}}$ value between 0 and $100 \%$. However, it is assumed that the terms of intensity in Eq. (4) satisfy the proportional relation to each other. As the terms in Eq. (4), on the other hand, must obey Lambert-Beer's non-linear relation, the $S_{\mathrm{O}_{2}}$ value calculated from Eq. (4), which will be referred to as $S_{c}$, is not perfectly identical with the real $S_{\mathrm{O}_{2}}$ or $S_{t}$. Thus, for obtaining the real $S_{\mathrm{O}_{2}}$ the difference between $S_{c}$ and $S_{t}$ must be investigated.

The extinction coefficient $\varepsilon_{2}$ in Eq. (2) is given by,

$$
\varepsilon_{\lambda}=\varepsilon_{\lambda 0}\left(1-S_{t}\right)+\varepsilon_{\lambda 1} \cdot S_{t},
$$

where $\varepsilon_{\lambda 0}$ and $\varepsilon_{\lambda 1}$ are the extinction coefficients of reduced and oxygenated hemoglobin, respectively. From Eqs. (2), (3), (4), and (5), the following equation is derived:

$$
S_{c}=\left[\left(\bar{d}-\varepsilon_{\lambda 0} \cdot c \cdot \bar{d}^{2}\right) \cdot S_{t}-c \cdot \bar{d}^{2} \cdot \sigma \varepsilon_{\lambda} \cdot S_{t}^{2} / 2\right] / \varphi,
$$

where

$$
\varphi=\bar{d}-c \cdot \bar{d}^{2}\left(\sigma \varepsilon_{\lambda}+2 \varepsilon_{\lambda 0}\right) / 2, \text { and } \sigma \varepsilon_{\lambda}=\varepsilon_{\lambda 1}-\varepsilon_{\lambda .0},
$$

and terms beyond the third are neglected. The error caused by neglected terms is less than about $1 \%$.

The $S_{c}$ value of Eq. (6) is obtained by giving the value of $\bar{d}, \bar{d}^{2}, \varepsilon_{20}, \varepsilon_{\lambda 1}$ and $c$. We attempted to evaluate $\bar{d}$ and $\bar{d}^{2}$ in a human red cell by referring to the crosssectional diagram and the volume of a single red cell described by PONDER (1955). As a result, $\bar{d}=1.76 \mu$ and $\bar{d}^{2}=3.40 \mu^{2}$ were obtained. The concentration of hemoglobin in the red cell is estimated to be $5.01 \times 10^{-3} \mathrm{~mol} / \mathrm{liter}$ from the data obtained by Ponder (1948). In order to obtain the $\varepsilon$ value of a single red cell, we measured $I / I o$ at $418 \mathrm{~nm}$ using present apparatus. We put the red cell in a reaction cuvette and measured the above ratio at fully oxygenated and deoxygenated states, and then calculated $\varepsilon$ by dividing $\log (I / I o)$ by $c \cdot \bar{d}$. The $\varepsilon$ values thus obtained at 


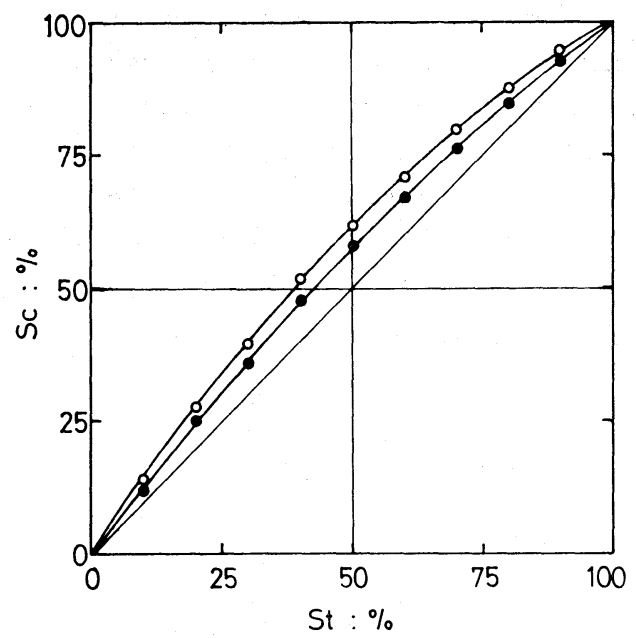

Fig. 5. Relationship between $S_{c}$ and $S_{t}$. Upper (O) and lower ( $\bullet$ curves were obtained by assuming that a red cell had a biconcave shape and uniform thickness.

the 0 and $100 \% S_{\mathrm{O}_{2}}$ were $3.2 \times 10^{5}$ and $4.1 \times 10^{5} \mathrm{~cm}^{2} \cdot \mathrm{mol}^{-1}$, respectively. The $\varepsilon_{20}$ and $\varepsilon_{21}$ values obtained by HUNTER (1951) were $2.6 \times 10^{5}$ and $3.8 \times 10^{5} \mathrm{~cm}^{2}$. $\mathrm{mol}^{-1}$. The difference between the values obtained by Hunter and by us may be considered as follows; we measured the extinction coefficient of the red cell instead of obtaining the extinction coefficient in a $\mathrm{Hb}$ solution, and the filter used in the present apparatus had a bandwidth of about 15 to $20 \mathrm{~nm}$. By substituting the above values into Eq. (6) the relation between $S_{c}$ and $S_{t}$ can be obtained and depicted as an upper curve in Fig. 5. A lower curve was obtained by assuming that the red cell had uniform thickness in the following dimensions; $\bar{d}=1.76 \mu$ and $\bar{d}^{2}=(\tilde{d})^{2}=3.10 \mu^{2}$. This figure clearly shows the effect of non-uniformity on the $S_{c}$ values. The $S_{c}$ values calculated at the two states of $\bar{d}^{2}=3.40 \mu^{2}$ and $3.10 \mu^{2}$ became a little larger at about $50 \% S_{\mathrm{O}_{2}}$ than the $S_{t}$ values. The deviation was about $12 \%$ in $S_{\mathrm{O}_{2}}$. The values of the biconcave model were greater than those of the sheet model. The difference between the $S_{c}$ values in uniform and non-uniform red cell models was not larger than $4 \%$.

\section{RESULTS}

\section{1) Measurement of $\mathrm{O}_{2}$-saturation}

For an actual reaction measurements the blood from healthy human adults was used. An extremely small amount of blood was put on the glass slide of the cuvette, a small piece of silicone rubber membrane $(25 \mu$ thick) was placed over it and the membrane was gently pressed, using the gauze, to expel the excess blood. This procedure was useful for forming a single layer on the glass slide surface and, on the other hand, the membrane prevented the preparation sample from drying 
during measurement. After placing the reaction cuvette on the movable stage, the red cells were brought into focus and a single red cell was illuminated by controlling the stage and the iris diaphragm. The output voltages from the photomultipliers were balanced with the potentiometer. The red cells in the cuvette were saturated with $\mathrm{O}_{2}$ in air at this stage, an $\mathrm{O}_{2}$-free-gas mixture of $\mathrm{N}_{2}$ and $\mathrm{CO}_{2}$ was first released into the cuvette in order to deoxygenate the red cell preparation. After reaching complete deoxygenated level, various $\mathrm{O}_{2}$ gas mixtures with different

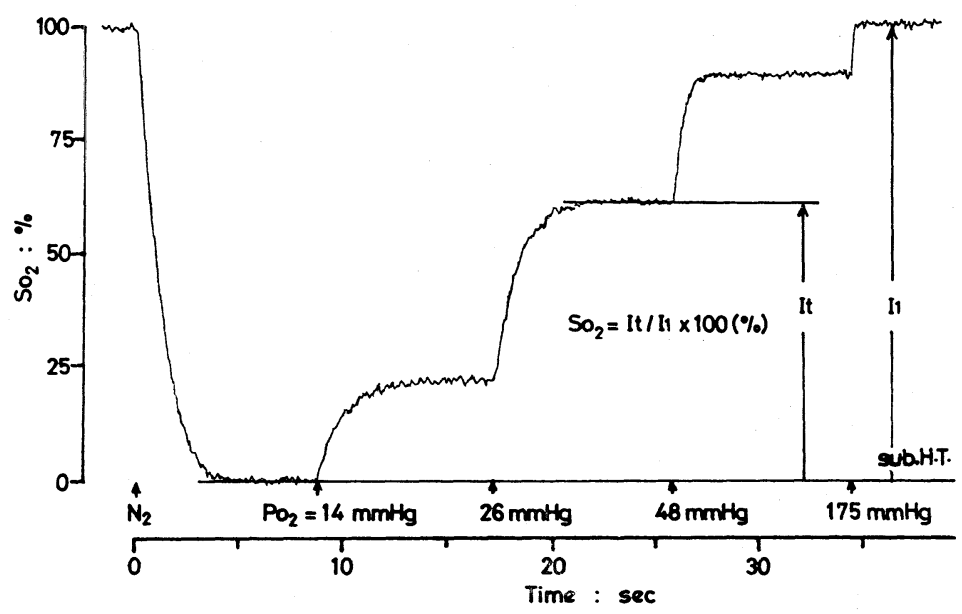

Fig. 6. $S_{\mathrm{O}_{2}}$ pattern of oxygenation and deoxygenation recorded when five gas mixtures with $0,14,26,48$, and $175 \mathrm{mmHg} P_{\mathrm{O}_{2}}$ with $40 \mathrm{mmHg} P_{\mathrm{CO}_{2}}$ were supplied successively.

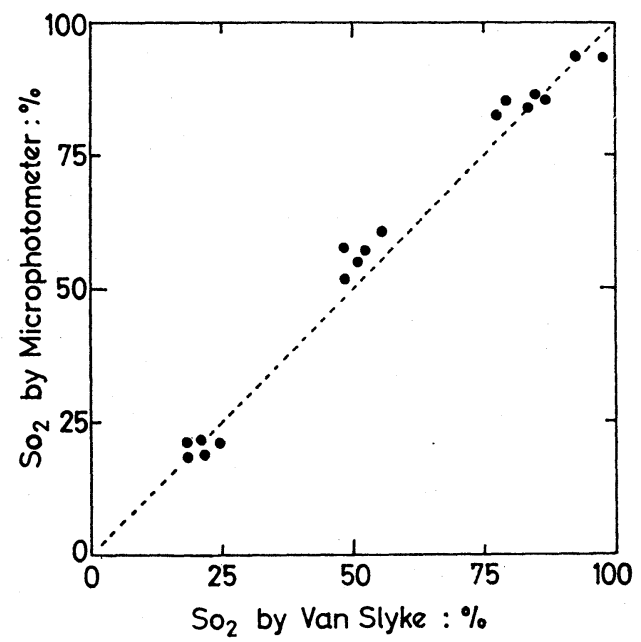

Fig. 7. Relationship between $S_{\mathrm{O}_{2}}$ values obtained with the present microphotometer and the Van-Slyke apparatus, respectively, with the same human blood sample. 
$\mathrm{O}_{2}$ concentrations were introduced, where the $\mathrm{CO}_{2}$ concentration was kept constant. Figure 6 shows the reaction pattern when five gas mixtures with $0,14,26$, 48, and $175 \mathrm{mmHg} P_{\mathrm{O}_{2}}$ with $40 \mathrm{mmHg} P_{\mathrm{CO}_{2}}$ were supplied successively. From this curve the $S_{c}$ could be calculated at each level of $P_{\mathrm{O}_{2}}$ by using Eq. (4). Figure 7 shows the comparison between $S_{c}$ and $S_{\mathrm{O}_{2}}$ obtained by the Van-Slyke method. As shown in Fig. 7 the $S_{c}$ value tended to be a little larger than the $S_{\mathrm{O}_{2}}$ value obtained by the Van-Slyke method around the half saturation point. A similar trend discussed theoretically in the previous section is shown, in other words, the error here may be mainly due to the non-linearity of Lambert-Beer's law. In addition, the fact that scattering does occur further compounds the problems. Unfortunately, it is not an easy matter to reduce the error factor. However, the difference between the $S_{\mathrm{O}_{2}}$ measured by the Van-Slyke method and the microphotometer may not give rise to an error larger than 3 to $4 \%$. In a small range of $S_{\mathrm{O}_{2}}$, the changing rate of $S_{\mathrm{O}_{2}}$ was indifferent to the non-linearity of the $S_{\mathrm{O}_{2}}$ calibration curve. In the actual measurement of the reaction velocity the $S_{\mathrm{O}_{2}}$ value measured by the microphotometer was treated as representing the true $S_{\mathrm{O}_{2}}$ value.

\section{2) Measurement of deoxygenation and oxygenation velocity}

The deoxygenation of the red cell was carried out by flushing the $\mathrm{O}_{2}$-free-gas mixture with $\mathrm{N}_{2}$ and $\mathrm{CO}_{2}$. The desaturation curve is shown in Fig. 6, where the $\mathrm{O}_{2}$-saturation decreases as the dissociation proceeds, starting from a plateau of $100 \%$ and finally reaching the $0 \%$ level.

According to MochizUKI (1966a) the reaction velocity was expressed, as a function of the velocity factor $(F c)$, by,

$$
F c=\frac{\mathrm{O}_{2} \text {-capacity }}{\text { hematocrit }} \frac{d S_{\mathrm{O}_{2}} / d t}{100\left(P c \sim P_{A}\right)},
$$

where the quotient of $\mathrm{O}_{2}$-capacity divided by hematocrit implies the $\mathrm{O}_{2}$ volume combining with $1 \mathrm{ml}$ red cells when the $S_{\mathrm{O}_{2}}$ increases by $1 \%$, and $P c$ and $P_{A}$ are

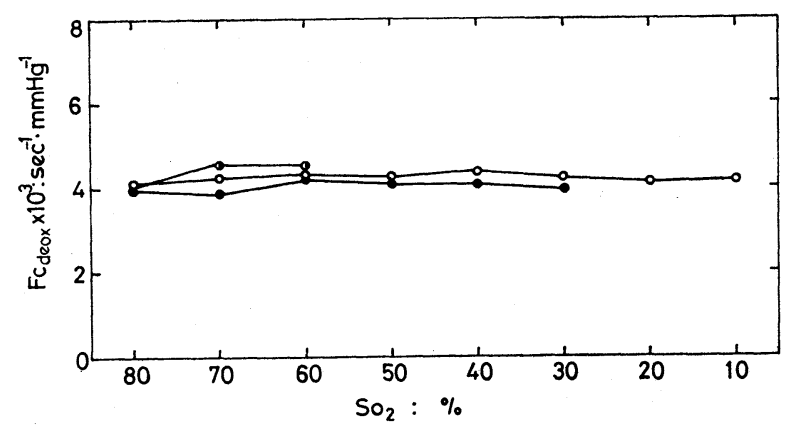

Fig. 8. $F c_{\text {deox }}$ values plotted against $S_{\mathrm{O}_{2}}$. : deoxygenation was measured in $P_{\mathrm{O}_{2}}$ range of 100 to $25 \mathrm{mmHg}$ (sub. K.Y.). $\bigcirc$, 0 : deoxygenation in $P_{\mathrm{O}_{2}}$ range of 100 to $0 \mathrm{mmHg}$ (sub. ○: T.O., ०: H.T.). 
the $\mathrm{O}_{2}$ tension in the red cell and in the gas phase. The changing rate $d S_{\mathrm{O}_{2}} / d t$ during the reaction is calculated from the slope of the oxygenation curve. The $P c$ was obtained from the $\mathrm{O}_{2}$-dissociation curve of the blood by referring to the $S_{\mathrm{O}_{2}}$. Figure 8 represents the results of the deoxygenation velocity factor $\left(F c_{\text {deox }}\right)$ plotted against the $S_{\mathrm{O}_{2}}$. The $F c_{\text {deox }}$ is distributed around the value of $0.0042 \mathrm{sec}^{-1}$. $\mathrm{mmHg}^{-1}$ and is independent of $S_{\mathrm{O}_{2}}$. After the red cell was reduced, the oxygenation reaction was started by introducing the $\mathrm{O}_{2}$ gas mixtures into the cuvette. The saturation curve due to the oxygenation is shown in Fig. 6 . The oxygenation velocity factor $\left(F c_{\mathrm{ox}}\right)$ plotted against the $S_{\mathrm{O}_{2}}$ are shown in Fig. 9. The $F c_{\text {ox }}$ in a $S_{\mathrm{O}_{2}}$ range of 0 to $70 \%$ is about $0.0045 \mathrm{sec}^{-1} \cdot \mathrm{mmHg}^{-1}$, showing a tendency of decreasing with the increase of $S_{\mathrm{O}_{2}}$ as described by MocHIzUKI (1966a).

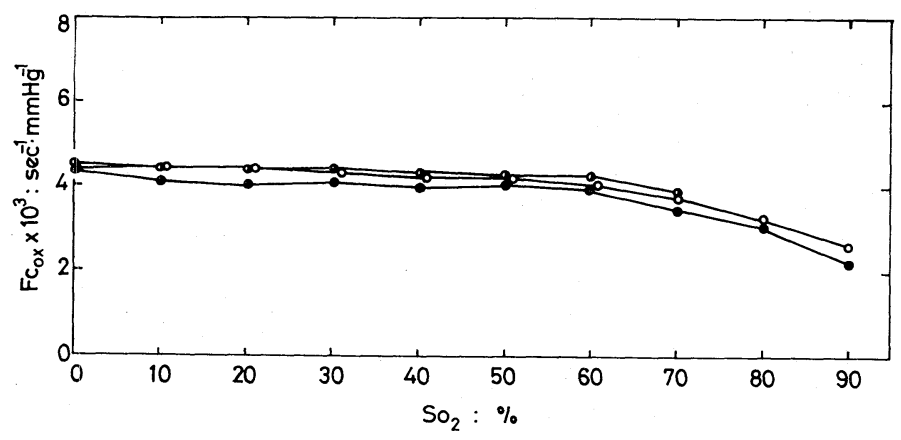

Fig. 9. $F c_{\text {ox }}$ values plotted against $S_{\mathrm{O}_{2}}$. $\quad$ : oxygenation was measured in $P_{\mathrm{O}_{2}}$ range of 0 to $48 \mathrm{mmHg}$ (sub. Y.M.). $\bigcirc, \bullet$ : oxygenation in $P_{\mathrm{O}_{2}}$ range of 0 to $100 \mathrm{mmHg}$ (sub. $\bigcirc$ : T.O.,

: H.T.).

\section{DISCUSSION}

A significant feature of the present apparatus is that the reaction could be measured while the red cells are in close contact with the reagent gases, unlike a flow method where the reaction was made by mixing a saline solution with a red cell suspension. Consequently, the gas concentration around the red cells could be kept constant throughout the measurement. This fact could overcome the difficult and troublesome problems that usually appear with the conventional flow method.

In the measurement of deoxygenation velocity, for instance, dithionite solution has often been used to liberate $\mathrm{O}_{2}$ from $\mathrm{O}_{2} \mathrm{Hb}$ in a red cell suspension. However, by-products in dithionite oxidation can react with hemoglobin, and this reaction can invalidate the measurement of deoxygenation velocity. In cases in which deoxygenation occurs by mixing the oxygenated red cell suspension with an $\mathrm{O}_{2}$-free solution, the measurable $S_{\mathrm{O}_{2}}$ range is restricted by $P_{\mathrm{O}_{2}}$ in solution after mixing, and the deoxygenation does not occur over a wide $S_{\mathrm{O}_{2}}$ range.

The present apparatus has another advantage in making possible the deter- 
mination of reaction rate in a single red cell. It may be a desirable method for studying the differences in $F c$ values caused by cell form changes or cell sizes or cell diseases.

As discussed theoretically, the non-linear characteristics of the $S_{\mathrm{O}_{2}}$ calibration curve may be due to the non-linearity of the Lambert-Beer's law and the nonuniformity of the cell thickness. The error caused by the non-uniform thickness may certainly be reduced by narrowing the spot size and illuminating only a small part in the red cell, where the thickness is expected to be uniform. Figure 5 shows that the influence of the thickness non-uniformity on the calibration curve may not be serious, so far as the incident light is injected in the normal direction to the disk surface. In the experiment for measurement of oxygenation or deoxygenation velocity, the $S_{\mathrm{O}_{2}}$ value measured by the microphotometer was treated as representing the true $S_{\mathrm{O}_{2}}$, and only a slight percentage error in $F c$ value was found.

In the present method the red cell must be placed on the glass slide in such a way that a single cell layer can be made. Since the red cells in such a thin film easily dries up, the preparation sample was covered by a thin $25 \mu$ thick transparent silicone membrane. Although the silicone membrane shows excellently permeability to gases, it is of great importance to know the effect of the membrane on the reaction rate for correcting measured velocity values. It is still difficult to obtain the solution of partial differential equation for the boundary conditions under which the red cells are put on a glass slide and covered with a resistive membrane. For simplicity, we obtained a diffusion equation with the boundary conditions in which the red cells are covered by a boundary layer with a unique and uniform transfer coefficient $\eta$, as described by MochIzUKI (1975). According to the data on the diffusion coefficient and solubility of the silicone membrane (LEE and Neville, 1971) $\alpha \cdot D$ for $\mathrm{O}_{2}$ is about $0.6 \times 10^{-8} \mathrm{~cm}^{2} \cdot \mathrm{sec}^{-1} \cdot \mathrm{mmHg}^{-1}$ which is about 6 times as great as that of water. The thickness of the membrane used was $25 \mu$. By using this value, the $\eta$ value of the membrane may be calculated as $\eta=0.24 \times 10^{-5} \mathrm{~cm} \cdot \mathrm{sec}^{-1} \cdot \mathrm{mmHg}^{-1}$ according to the following formula:

$$
\eta=\alpha \cdot D / \text { thickness of membrane. }
$$

In order to test the validity of the above $\eta$ value we measured the oxygenation velocity of a thin $\mathrm{Hb}$ solution layer, which was placed on a glass slide covered by the same membrane. The thickness of the layer was roughly estimated to be $4 \mu$ by means of a microscope technique. Figure 10 shows an actual record of the oxygenation curve of the $\mathrm{Hb}$ solution layer. The $\mathrm{Hb}$ solution was prepared from normal blood that had been frozen and thawed. From the oxygenation curve of Fig. 10, the $F c_{\text {ox }}$ (sol) value was calculated according to the following formula:

$$
F c_{\mathrm{ox}}(\mathrm{sol})=\mathrm{O}_{2} \text {-capacity } \frac{d S_{\mathrm{O}_{2}} / d t}{100\left(P a-P_{\mathrm{Hb}}\right)},
$$

where $P a$ and $P_{\mathrm{Hb}}$ are the $\mathrm{O}_{2}$ tensions in the solution and hemoglobin molecules, respectively. $\quad P_{\mathrm{Hb}}$ was read from the $\mathrm{O}_{2}$-dissociation curve of blood by referring 


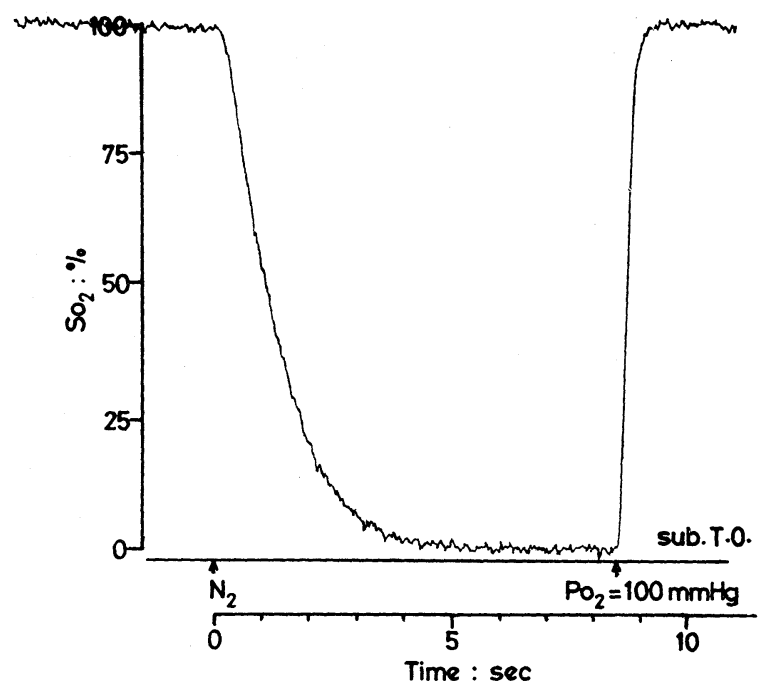

Fig. 10. An example of the reaction pattern in a Hb solution layer.

to the $S_{\mathrm{O}_{2}}$. The $F c_{\text {ox }}(\mathrm{sol})$ values were about $0.0025 \mathrm{sec}^{-1} \cdot \mathrm{mmHg}^{-1}$ at a $S_{\mathrm{O}_{2}}$ range of 20 to $70 \%$. According to MochizuKi and FukUoKa (1958) the $F c_{\text {ox }}$ value of one-dimensional diffusion at a steady diffusion state in a hypoxic level is given by,

$$
F c_{\text {ox }}=\alpha \cdot D \cdot \mu_{1}^{2} / d^{2},
$$

where $d$ is the thickness of the $\mathrm{Hb}$ solution layer and $\mu_{1}$ is the first eigen value which is given by,

$$
\mu_{1} \cdot \tan \mu_{1}=\eta \cdot d / \alpha \cdot D .
$$

The $\alpha \cdot D$ value in Eqs. (10) and (11) is that of the $\mathrm{Hb}$ solution, where the $\mathrm{O}_{2}$ dif-

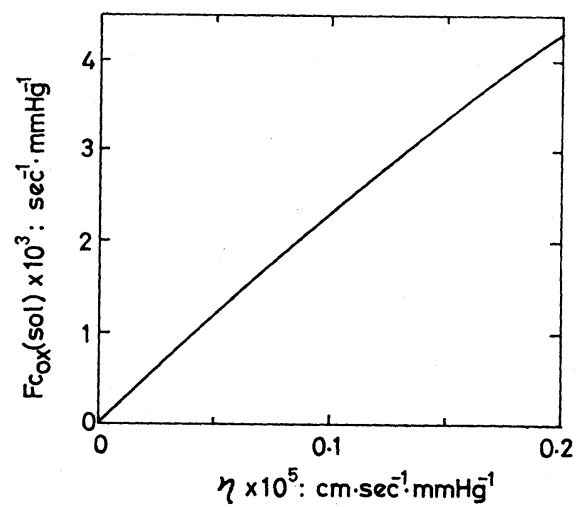

Fig. 11. Relationship between the $F c_{0 x}$ (sol) and $\eta$ values, where $F c_{\text {ox }}$ (sol) shows the $F c$ value of a $\mathrm{Hb}$ solution layer. 
fusion is facilitated by the movement of $\mathrm{Hb}$ molecules as stated by SCHOLANDER (1960). By referring to the data of SCHOLANDER (1960), and GERTZ and LOESCHCKE (1954) the above $\alpha \cdot D$ is estimated to be $1.6 \times 10^{-9} \mathrm{~cm}^{2} \cdot \mathrm{sec}^{-1} \cdot \mathrm{mmHg}^{-1}$. By putting this value in Eqs. (10) and (11), the $F c_{\text {ox }}(\mathrm{sol})$ is shown as a function of the $\eta$ values as shown in Fig. 11, where the thickness of $\mathrm{Hb}$ solution layer was assumed to be $4 \mu$. From the measured $F c_{\text {ox }}$ (sol) value of $0.0025 \mathrm{sec}^{-1} \cdot \mathrm{mmHg}^{-1}$ the $\eta$ value of the silicone membrane is evaluated to be $0.11 \times 10^{-5} \mathrm{~cm} \cdot \mathrm{sec}^{-1} \cdot \mathrm{mmHg}{ }^{-1}$, which is about half the value estimated from Eq. (8). The velocity factor of oxygenation of the red cell at the steady diffusion state in hypoxic level is given by,

$$
F c_{\text {ox }}=\alpha \cdot D\left(\mu_{1}^{2} / d^{2}+\nu_{1}^{2} / r^{2}\right),
$$

where $d$ and $r$ are the thickness and radius of the red cell, and $\nu_{1}$ is the first eigen value given by,

$$
\nu_{1} J_{1}\left(\nu_{1}\right) / J o\left(\nu_{1}\right)=\eta \cdot r / \alpha \cdot D .
$$

Substituting the values of $d=0.8 \mu$ and $r=3.5 \mu$ into Eqs. (11), (12), and (13), we can derive the $F c_{\text {ox }}$ values as a function of the $\eta$ value in two cases where the diffusion takes place across the one side (lower curve) and/or both the sides (upper curve) of the disk surface. Figure 12 shows the two $F c_{\text {ox }}$ values against the $\eta$

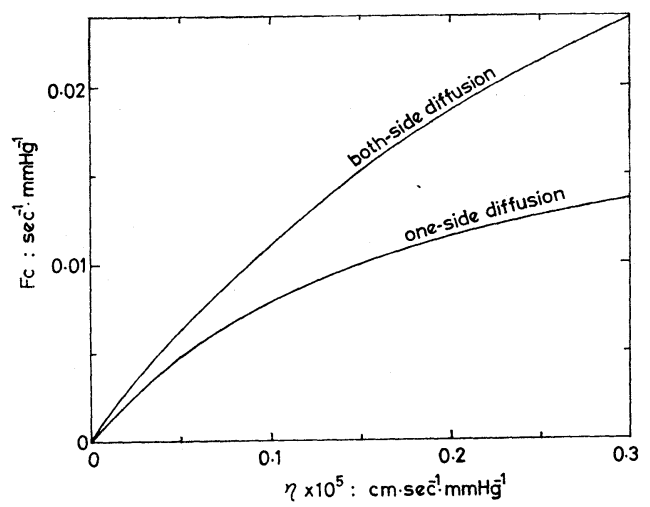

Fig. 12. Relationship between the $F c_{o x}$ and $\eta$ values. The upper and lower curves show the $F c_{\text {ox }}$ values obtained when the diffusion takes place through both-side and one-side of the disk surface, respectively.

value, where $\alpha \cdot D$ for $\mathrm{O}_{2}$ was taken to be $1.45 \times 10^{-10} \mathrm{~cm}^{2} \cdot \mathrm{sec}^{-1} \cdot \mathrm{mmHg}^{-1}$ according to KLUG et al. (1956). The one- and both-side diffusion may be observed in cases of the present method and in a red cell suspension, respectively. The $F c_{\text {ox }}$ measured in the experiment of Fig. 9 was $0.0045 \mathrm{sec}^{-1} \cdot \mathrm{mmHg}^{-1}$, and the $\eta$ value corresponding this measured $F c_{\text {ox }}$ value can be obtained as $\eta=0.05 \times 10^{-5} \mathrm{~cm}$. $\mathrm{sec}^{-1} \cdot \mathrm{mmHg}^{-1}$ by using the theoretical $F c_{\text {ox }}$ variation as to $\eta$ which is shown by the lower curve in Fig. 12. Provided that the total $\eta$ value consists of two $\eta$ values 
of the membrane and the plasma-cell interface and the following relation between them roughly holds:

$$
1 / \eta_{\text {over-a11 }}=1 / \eta_{\text {membrane }}+1 / \eta_{\text {plasma-cel1 }},
$$

where the latter $\eta_{\text {plasma-cell }}$ value will be evaluated to be $0.09 \times 10^{-5} \mathrm{~cm} \cdot \mathrm{sec}^{-1}$. $\mathrm{mmHg}^{-1}$. The above numerical relation is summarized in Table 1. Using the $\eta$ value at the plasma-cell interface we can further estimate the $F c_{\text {ox }}$ value in the state in which the red cells are floating in a stationary fluid. The velocity factor of the both-side diffusion at $\eta=0.09 \times 10^{-5} \mathrm{~cm} \cdot \mathrm{sec}^{-1} \cdot \mathrm{mmHg}^{-1}$ can be read from the upper curve of Fig. 12 to be $0.0101 \mathrm{sec}^{-1} \cdot \mathrm{mmHg}^{-1}$, showing a good agreement with the value obtained by KoyAmA and MochizUKi (1967) by means of the stopped flow method. Using the same thickness of the $\mathrm{Hb}$ solution layer, we further calculated the $\eta$ value of the membrane in reverse direction, i.e. in a deoxygenation process. Then, $F c_{\text {deox }}(\mathrm{sol})=0.0015 \mathrm{sec}^{-1} \cdot \mathrm{mmHg}^{-1}$ and $F c=0.0103 \mathrm{sec}^{-1}$. $\mathrm{mmHg}^{-1}$ were obtained as shown in Table 1 .

Table 1. Relationship between the $F c$ and $\eta$ values.

\begin{tabular}{llccc}
\hline & & \multicolumn{2}{c}{ Red cell } & Hemoglobin \\
\cline { 3 - 5 } & & over-all & cell suspension & \begin{tabular}{c} 
solution \\
\hline \multirow{2}{*}{ Oxygenation }
\end{tabular} \\
& $\eta \times 10^{5}\left(\mathrm{~cm} \cdot \mathrm{sec}^{-1} \cdot \mathrm{mmHg}^{-1}\right)$ & 0.05 & 0.09 & 0.11 \\
& $F c \times 10^{2}\left(\mathrm{sec}^{-1} \cdot \mathrm{mmHg}^{-1}\right)$ & 0.45 & 1.01 & 0.25 \\
\hline \multirow{2}{*}{ Deoxygenation } & $\eta \times 10^{5}\left(\mathrm{~cm} \cdot \mathrm{sec}^{-1} \cdot \mathrm{mmHg}^{-1}\right)$ & 0.04 & 0.093 & 0.07 \\
& $F c \times 10^{2}\left(\mathrm{sec}^{-1} \cdot \mathrm{mmHg}^{-1}\right)$ & 0.42 & 1.03 & 0.15 \\
\hline
\end{tabular}

The authors thank Dr. Chiyoshi Yoshimoto, Professor, Res. Inst. Appl. Electr., for his useful advice and Dr. Masaji Mochizuki, Professor, Dept. of Physiology, School of Medicine, Yamagata University, for his constructive criticisms, useful suggestions and for his support, and Mr. Takashi Arai for his skilled technical assistance. We also thank Dr. Toshimitsu Asakura, Professor, Res. Inst. Appl. Electr., for his help in correcting the English in this manuscript.

\section{REFERENCES}

Forster, R. E., Roughton, F. J. W., Kreuzer, F., and Briscoe, W. A. (1957) Photocolorimetric determination of rate of uptake of $\mathrm{CO}$ and $\mathrm{O}_{2}$ by reduced human red cell suspensions at $37^{\circ} \mathrm{C}$. J. Appl. Physiol., 16: 519-527.

Fukui, K. and Mochizuki, M. (1972) Some basic problems on the pulmonary diffusing capacity for carbon monoxide. 1. The reaction rate of $\mathrm{CO}$ with oxygenated hemoglobin in the red cell. Monograph Series of Res. Inst. Appl. Electr., 20: 69-78.

Gertz, K. H. and Loeschcke, H. H. (1954) Bestimmung der Diffusions-Koeffizienten von $\mathrm{H}_{2}$, $\mathrm{O}_{2}, \mathrm{~N}_{2}$ und $\mathrm{He}$ in Wasser und Blutserum bei konstant gehaltener Konvektion. Z. Naturforsch., 96: 1-9.

Hartridge, H. and Roughton, F. J. W. (1923) A method of measuring the velocity of very rapid chemical reactions. Proc. Roy. Soc. A. 104: 376-394.

Hunter, F. T. (1951) The Quantitation of Mixtures of Hemoglobin Derivatives by Photoelectric Spectrophotometry. Chales. C. Thomas. Publ. Co., Springfield, Illinois, p. 107. 
Klug, A., Kreuzer, F., and Roughton, F. J. W. (1956) The diffusion of oxygen in concentrated hemoglobin solutions. Helv. Physiol. Acta, 14: 121-128.

Koyama, T. and Mochizuki, M. (1967) Application of the Pt-Polarography to the stopped-flow method for measuring of the oxygen uptake by red blood cell. Rev. Polarography (Japan), 14: $405-411$.

Koyama, T. and Mochizuki, M. (1969) A study on the relationship between the oxygenation velocity of red blood cell and the flow velocity in a rapid flow method. Jap. J. Physiol., 19: 534-546.

Lawson, W. H., Jr., Holland, R. A. B., and Forster, R. E. (1965) Effect of temperature on deoxygenation rate of human red cells. J. Appl. Physiol., 20: 141-156.

Lee, H. and Neville, K. (1971) Handbook of Biomedical Plastics. Pasadena Technology Press, Pasadena, California, pp. 2-20.

MochizuKi, M. (1966a) Study on the oxygenation velocity of the human red cell. Jap. J. Physiol., 16: 635-648.

MochIzUKI, M. (1966b) On the velocity of oxygen dissociation of human hemoglobin and red cell. Jap. J. Physiol., 16: 649-657.

MochIZUKI, M. (1975) Graphical Analysis of Oxygenation and CO Combination Rates of the Red Cells in the Lung. Hirokawa Shoten, Tokyo, in press.

MochizuKi, M. and FuKUokA, J. (1958) The diffusion of oxygen inside the red cell. Jap. J. Physiol., 8: 206-224.

Mochizuki, M., TaZaWa, H., and ONo, T. (1973) Microphotometry for determining the reaction rate of $\mathrm{O}_{2}$ and $\mathrm{CO}$ with red blood cells in the chorioallantoic capillary. In Oxygen Transport to Tissue, ed. by Bruley, D. F. and Bicher, H. I. Plenum Publ. Co., New York, pp. 997-1006.

Ponder, E. (1948) Hemolysis and Related Phenomena. Grune and Stratton Publ. Co., New York, p. 120.

PonDER, E. (1955) Red cell structure and its breakdown. Protoplasmatologia. Band 12, Springer-Verlag, Wien, p. 4.

Scholander, P. F. (1960) Oxygen transport through hemoglobin solutions. Science, 131: 585-590.

Staub, N. C., Bishop, J. M., and Forster, R. E. (1961) Velocity of $\mathrm{O}_{2}$ uptake by human red blood cells. J. Appl. Physiol., 16: 511-516.

TAZAWA, H., ONo, T., and Mochizuki, M. (1974) Reaction velocity of carbon monoxide with blood cells in chorioallatoic vascular plexus of chicken embryo. Resp. Physiol., 20: 161-170. 